\title{
LA RACIONALIDAD DE LA PONDERACIÓN EN LA ARGUMENTACIÓN CONSTITUCIONAL*
}

Juan M. Mocoroa**

Fecha de recepción: 5 de diciembre de 2015

Fecha de evaluación: 15 de marzo de 2016

Fecha de aprobación: 12 de mayo de 2016

Artículo de reflexión

DOI: http://dx.doi.org/10.18359/prole.2724

Forma de citación: Mocoroa, J.M. (2017). La racionalidad de la ponderación en la argumentación constitucional. Revista Prolegómenos Derechos y Valores, 20, 39, 73-85. DOI: http://dx.doi.org/10.18359/prole.2724

\section{Resumen}

En este artículo se defiende una forma de eludir la objeción de que la ponderación es irracional. Para esto, se sostiene que ella debe entenderse como una simple "estructura formal" para el análisis de decisiones judiciales dictadas en casos de conflictos de derechos. Sin embargo, eso no implica que en este ámbito no existan posibilidades para la discrecionalidad y los juicios subjetivos.

\section{Palabras clave:}

Ponderación, conflicto de derechos, racionalidad argumentativa, discrecionalidad judicial.

\section{THE RATIONALITY OF THE WEIGHTING IN THE CONSTITUTIONAL ARGUMENT}

\begin{abstract}
Summary
This article defends a way to bypass the objection that the weighting is irrational. To do this, it is argued that it should be understood as a simple "formal structure" for the analysis of judicial decisions rendered in cases of disputes over rights. However, it does not imply that in this field there do not exist possibilities to the discretion and the subjective judgements.
\end{abstract}

\section{Keywords:}

Weighting, conflict of rights, argumentative rationality, judicial discretion.

Este trabajo se enmarca en el proyecto de investigación tipo II "La Constitución Nacional ante el Tribunal Superior de Justicia de Córdoba: control de constitucionalidad e interpretación constitucional" llevado a cabo en la Universidad Siglo 21 (Córdoba, Argentina) y cuya dirección está a cargo del autor.

" Abogado por la Universidad Nacional de Córdoba (UNC) (Córdoba, Argentina), máster en Global Rule of Law and Constitutional Democracy (Universidad de Génova, Italia), máster en Derecho y Argumentación Jurídica (UNC); doctorando en Derecho y Ciencias Sociales (UNC), docente Derecho Constitucional en UNC y en Derecho Procesal IV (Universidad Siglo21) (Córdoba, Argentina). Miembro de la Asociación Argentina de Derecho Constitucional. El autor agradece los comentarios a versiones en borrador de este trabajo a Guadalupe Valcarce Ojeda, Martín Juárez Ferrer y, en especial, a Pedro A. Caminos. Correo electrónico: jmmocoroa@gmail.com 


\title{
A RACIONALIDADE DA PONDERAÇÃO NA ARGUMENTAÇÃO CONSTITUCIÓNAL
}

\begin{abstract}
Resumo
Neste artigo é defendida uma forma de esquivar a objeção de que a ponderação é irracional. Para isto, é sustentado que ela deve ser entendida como uma simples "estrutura formal" para a análise de decisões judiciais ditadas em casos de conflitos de direitos. Porém, isso não implica que neste âmbito não existam possibilidades para a discricionariedade e os juízos subjetivos.
\end{abstract}

\section{Palavras-chave:}

Ponderação, conflito de direitos, racionalidade argumentativa, discricionariedade judicial.

\section{Introducción}

En este breve trabajo analizo la relevancia de una estrategia muy difundida para la resolución de los conflictos de derechos, la llamada "ponderación" o balancing. Vale decir, el mecanismo para la resolución de los conflictos entre principios jurídicos según el cual debe prevalecer el principio que cuente con mayor peso dadas las circunstancias particulares del caso (Martínez, 2010). Se trata de una estructura argumentativa usualmente invocada tanto por los dogmáticos que se ocupan de estudiar los conflictos entre "derechos fundamentales", como por diversos tribunales constitucionales.

Es en este sentido que se tiende a pensar a la ponderación como un procedimiento correcto que cualquier tribunal debería emplear para proceder a la interpretación y aplicación de las normas sobre derechos fundamentales contenidas en las modernas Constituciones ${ }^{1}$. Es más, podría decirse que el centro del debate actual sobre la argumentación constitucional, al menos, se refiere a dos temas vinculados a ella: (i) cómo establecer restricciones a la actuación del juez constitucional en caso de que recurra a esta estrategia argumentativa y (ii) cómo garantizar

1 Sobre esta consecuencia de la generalización del empleo de esta técnica y cuáles son los problemas teóricos y normativos que acarrea la misma, véase Caminos (2014). que las decisiones a las que arribe, producto de la ponderación, sean racionales y no basadas exclusivamente en su subjetividad y voluntad. Aquí se defenderá que debe ser entendida como una "estructura formal" de razonamiento que admite el control en cada uno de sus pasos; más allá de la discusión, por otra parte, de si se trata de un supuesto de interpretación o construcción constitucional $^{2}$.

\section{A. Presentación}

Aun cuando es cierto que hay un uso generalizado de esta estrategia, no lo es menos que la ponderación recibió numerosas objeciones; conceptuales y normativas. En particular, me parece, podrían presentarse dos críticas que se convirtieron en canónicas ${ }^{3}$ : (i) no podría asegurar, pese a su declamado objetivo, racionalidad en la

2 Sobre la distinción, en la literatura americana, entre constitutional interpretation y constitutional construction véase entre muchos otros a Balkin (2011). La primera sería la adscripción de un significado a un término constitucional; la segunda, radica en la implementación y aplicación de la Constitución a través de diversas modalidades. Guastini (2014) específicamente refiere que la ponderación no implica una estrategia interpretativa -i. e. adscripción de significado- sino que se trata de un supuesto de construcción jurídica; dado que, en rigor, ella no dice nada respecto del contenido normativo de las disposiciones constitucionales que expresan los principios.

3 Sobre la noción de canon en el derecho constitucional el locus clásico es Balkin y Levinson (2010). 
argumentación constitucional; y además, (ii) no podría justificar los resultados a los que arriba. Aun cuando creo que se trata de un problema muy importante, aquí no lo analizaré (ii) ${ }^{4}$.

En este artículo sostendré que existe una forma de eludir la objeción indicada en (i). Para eso, en primer lugar, haré un rápido repaso de las concepciones que defienden los diferentes autores en cuanto al lugar que le cabe a la ponderación en la interpretación y argumentación constitucional. De tal manera, me referiré a las normas de derechos fundamentales qua principios normativos y a las posibilidades de conflictos de derechos. Más tarde reconstruiré las objeciones genéricas a este mecanismo argumentativo. Finalmente, para responder a estas críticas, propondré pensar a la ponderación como una simple "estructura formal" de análisis de decisiones judiciales dictadas en casos de conflictos de derechos. De este modo, en algún sentido, la ponderación sería útil a los efectos de la construcción dogmática de estructuras argumentativas previsibles y objetivas ${ }^{5}$.

Ahora bien, que el mecanismo pueda entenderse de esta forma, de ningún modo implica que esté en condiciones de evitar la discrecionalidad y los juicios subjetivos del juez. Pero estos últimos supuestos se darán en el marco de la determinación de las premisas del razonamiento judicial; en particular, al momento de la determinación de los significados de las disposiciones normativas en las que está formulado el derecho. Vale mencionar, que pueda salir airosa de la objeción -i. e., la presunta irracionalidad- no dice nada sobre la corrección de la "crítica de la discrecionalidad".

En suma, aduciré que la proporcionalidad o ponderación, en tanto estructura formal, no es per se irracional; incluso cuando no pueda

\footnotetext{
Sobre este problema véase Habermas (1998).

Adviértase que cuando se emplea el adjetivo "objetivas" se hace a los efectos de referirse a la estructura argumentativa en sí misma y qua organización formal del razonamiento judicial. Y no, por el contrario, respecto de los resultados concretos a los que arriba el decisor.
}

evitar una fuerte presencia de juicios subjetivos y discrecionales de parte del juez. Ahora bien, si esto fuera cierto, el interrogante que surge a primera vista es por las razones que justifican la actuación de un juez en estos casos y su legitimidad y vinculación respecto de los poderes más democráticos del Gobierno.

Pero, por supuesto, esto es absolutamente independiente del problema que se plantea. Por lo que aquí no me ocuparé de él in extenso; solo lo mencionaré. De todas formas, antes creo necesario hacer algunas consideraciones previas a cuáles son las, por llamarlas de algún modo, "circunstancias de la ponderación". De ello me ocuparé seguidamente.

\section{B. Las "circunstancias de la ponderación": conflictos de derechos}

En líneas generales, se cree que la ponderación es una metodología adecuada para evaluar la corrección de los argumentos y decisiones que toman los jueces constitucionales en los casos de conflicto entre principios que expresan derechos fundamentales (Bernal, 2005a) ${ }^{6}$. Ante la presencia de un conflicto de derechos, debería recurrirse a este mecanismo para su resolución. Como sostiene Martínez (2010, p. 154), existe un "núcleo conceptual mínimo" de la ponderación que consistiría en atribuir un determinado nivel de peso o importancia a cada uno de los elementos en conflicto en las circunstancias del caso a decidir.

Adviértase bien que esa adscripción de peso es relativa al caso a decidir y no, por el contrario, en abstracto. Es así como, únicamente, la ponde-

$6 \quad$ Bernal (2006) argumenta que la proporcionalidad, al igual que la razonabilidad y la racionalidad, es un criterio para la valoración correcta de los argumentos interpretativos de las disposiciones legislativas y constitucionales $y$, de este modo, para la fundamentación adecuada de las decisiones que se adoptan en el control de constitucionalidad. Así mismo, en otros trabajos sostuvo que la ponderación es un "criterio metodológico básico para la aplicación jurídica" de los derechos fundamentales. 
ración determina cuál de estos elementos vence sobre el otro u otros y resuelve el caso ${ }^{7}$. Ahora bien, lo que aquí denomino las "circunstancias de la ponderación" impondrían la necesidad de recurrir a esta estrategia. Así deben resaltarse, según la dogmática de los derechos, tanto (i) las características de las normas que adscriben derechos fundamentales, como (ii) las posibilidades de colisión y su resolución.

\section{Las piezas de los derechos fundamen- tales; principios, no reglas ${ }^{8}$}

El ámbito de actuación de esta estrategia, como dije, lo brindan los casos de conflictos de derechos. Ese es el locus usual en el que se piensa y estudia la ponderación. En particular, dada su estructura que los asemeja a la noción de principios y no a la de reglas ${ }^{9}$. Nótese que ellos son expresados por las Constituciones en normas que son particularmente abiertas y que no determinan una consecuencia normativa precisa; de ahí que Alexy (2008), por ejemplo, exprese que se trata de "mandatos de optimización" que ordenan que algo sea realizado en la mayor medida posible según las posibilidades jurídicas y fácticas de que se trate (Bernal, 2005b).

En palabras de Ruiz (2009, p. 99) "ponderación es precisamente el nombre de la operación destinada a determinar el peso relativo, en relación con las propiedades de un cierto caso, de diversos principios en concurrencia".

8 Como es obvio y sabido, el sintagma "las piezas del derecho" no me pertenece, véanse Atienza y Ruiz (1996).

9 Es usual en la teoría de los derechos fundamentales contemporánea distinguir entre dos tipos de normas, reglas y principios. Dudas sobre la distinción en Guastini (2007). Este autor señala que los juristas suelen emplear el concepto de principio, al menos, en los siguientes sentidos: (i) como normas fundamentales -i. e., caracterizan al sistema jurídico, dan fundamento axiológico a una pluralidad de normas, se conciben como una especie de axioma-; y (ii) como normas estructuralmente indeterminadas que pueden asumir dos formas distintas: (a) normas derrotables -i. e., no establecen exhaustivamente los hechos condicionantes, o bien no enumeran todas las excepciones- $y$ (b) normas genéricas -i. e., exigen la formulación de otras normas para su aplicación y pueden concretizarse en formas muy diferentes y alternativas-.
Obsérvese bien que los principios constitucionales tienen algunas características que los distinguen. Como sostiene Guastini (2014), (i) no tienen un campo de aplicación determinado, por lo que es una cuestión controvertida si un principio se aplica a un cierto caso; (ii) no establecen soluciones unívocas para las cuestiones de derecho; $y$, además, (iii) aun cuando puedan ser aplicables a un caso, puede ser que no se apliquen. Vale decir, (i) puede controvertirse que un principio constitucional sea aplicable a un caso; (ii) incluso cuando exista acuerdo, pueden debatirse las soluciones normativas que ellos determinan pues, en rigor, no hay acuerdo respecto de si el supuesto fáctico previsto se encuentra dentro del alcance del principio. Entonces, no sería posible comprender la importancia de los principios para la argumentación constitucional si no se asumen las siguientes premisas:

1. Los derechos fundamentales se expresan en principios.

2. Estos son estructuralmente distintos de las reglas -que son aplicadas a través de la subsunción-.

3. Solo puede aplicárselos a través de la ponderación.

El punto sería entonces el siguiente: si es cierto que ambos tipos de normas poseen una estructura diferente, debería colegirse que el modo de aplicación requiere una metodología también diferenciada. Es esto de lo que se ocupa la "ponderación"; brinda la estructura formal para la aplicación de los principios constitucionales en casos de conflictos. Y de allí su relevancia para la argumentación constitucional.

Dadas las características específicamente abiertas de los principios no podría aplicárselos como si se tratara de "reglas" -i. e., de modo subsuntivo-. A los efectos de su implementación concreta a un caso, es menester proceder a la especificación del principio de que se trate. Es que, como dice Guastini (2014), para que pueda ser aplicado a un caso individual es necesario extraer del mismo una regla lo suficientemente determinada como para servir de premisa al 
razonamiento práctico del juzgador. Ahora bien, por su característica indeterminación los principios suelen colisionar entre sí.

En estos casos, lo que sostiene ampliamente la dogmática de los derechos fundamentales es que en caso de conflictos entre derechos no debería recurrirse a la subsunción para solucionarlos ${ }^{10}$. De tal suerte, debe buscarse un método de aplicación alternativo: la "ponderación". Esto se vincula con las "piezas" de los derechos fundamentales. Es que, dado el carácter pluralista de las Constituciones modernas, estas pueden otorgar respuestas contradictorias sobre ciertos casos individuales.

Vale decir, las Constituciones modernas reconocen valores comprometidos con diferentes tradiciones ético-políticas y es por eso que, además, pueden ellos mismos entrar en conflicto. En este sentido, para algunos autores, no es facultativo recurrir a la ponderación. Por el contrario, si se admite la pluralidad de los valores, la indeterminación y la posibilidad de que ellos entren en conflicto, recurrir a la ponderación no es una acción facultativa para su resolución sino que, antes bien, es una necesidad lógica y conceptual ${ }^{11}$.

De este modo, y dado que ni existen jerarquías normativas ni axiológicas entre los derechos, al momento de resolver un conflicto entre ellos es forzoso determinar en ese caso y para ese supuesto fáctico cuál es el peso relativo de cada uno de ellos. Además, debe notarse, los

10 Por subsunción entiendo el procedimiento por el que se determina que un cierto caso individual es una instancia de un caso genérico al que una norma aplicable correlaciona con una cierta consecuencia normativa. Cfr. Orunesu (2012). En idéntico sentido, Moreso (2006).

11 En palabras de Barberis (2015, p. 120): "Si l'on admet la pluralité, l'indétermination et la conflictualité des valeurs morales et des principes constitutionnels, on ne voit pas de vraie alternative raisonnable au balancement. Il serait bien plus déraisonnable, à l'inverse, de masquer la multiplicité des principes pertinents et d'appliquer le principe choisi comme s'il n'était que le seul principe pertinent, comme le font les juges constitutionnels utilisant l'approche textualiste ou originaliste aux EtatsUnis". principios no son normas categóricas expresadas en condicionales hipotéticos que enlazan un supuesto de hecho con una consecuencia jurídica -i. e., si A debe ser B-y de carácter concluyente; al contrario, se trata de normas únicamente prima facie ${ }^{12}$.

El punto entonces es que se trata de una estructura formal, argumentativa, para ejercer el control de la aplicación de los principios que expresan normas de derechos fundamentales y, así, implantar "una relación de precedencia condicionada entre los principios en colisión, para así establecer cuál de ellos debe determinar la solución del caso concreto" (Bernal, 2005a, pp. 98-99) ${ }^{13}$. Esto puede hacerlo la ponderación debido a la estructura de las normas de los derechos fundamentales; además como producto de ello cuando estos son aplicados para la resolución de un conflicto no significa que uno de los principios sea inválido ni que se haya generado una excepción implícita a su aplicación ${ }^{14}$. Los principios, según los casos de

12 Sobre este punto, véase Moreso (2006).

13 Véase también, Orunesu (2012, p. 84) que, en el mismo sentido, siguiendo a Alexy habla de "relación de preferencia condicionada".

14 Una noción muy conflictiva, a tal punto que no es aceptada por todos los autores que se ocupan de estudiar el alcance de los derechos, es la de "conflictos" o "colisión". A tal fin, entiendo por "conflicto o contradicción normativa", "la situación que se produce cuando resulta lógicamente imposible para un sujeto satisfacer conjuntamente todos los contenidos normativos de las normas de obligación y cada uno de los contenidos normativos de las normas permisivas de un sistema de normas, dictadas por una cierta autoridad y en relación con una cierta ocasión" (Orunesu, 2012, p. 75). Repárese en que, por ejemplo, Ferrajoli (2012), uno de los autores más conspicuos defensores de nociones robustas de constitucionalismo y de los derechos fundamentales, sin embargo no cree que sea posible conceptualmente la existencia de conflictos. Para sostener esta posición recurre a la idea de jerarquía. Sobre las dificultades teóricas de esta posición, véanse Moreso (2005), Pino (2009) y Atienza (2012). Véase, por ejemplo, Ferrajoli (2012), aquí denuncia que el efecto no deseado de la ponderación es la eliminación del carácter tendencialmente cognoscitivo de la jurisdicción lo que, según él, desembocaría en una pérdida de la fuente de la legitimación de la jurisdicción dado que promovería su actuación discrecional lo que, a su vez, conduciría a la pérdida de normatividad o al debilitamiento de las Constituciones. 
que se trate, tienen distinto peso y el conflicto debe resolverse según esta dimensión y no por la de su validez (Moreso, 2010).

La ponderación establecería una relación de precedencia condicionada de acuerdo con las circunstancias fácticas del caso de que se trate. Esto es, dadas ciertas circunstancias uno de los principios precede al otro; sin embargo, esto no dice nada respecto a la jerarquía en abstracto de estos principios entre sí $^{15}$.

\section{La ponderación como estrategia formal}

Aquí, creo, puede encontrarse el carácter ambicioso y modesto a la vez de la ponderación. Como así también, su utilidad para la argumentación constitucional en los casos de colisión entre derechos fundamentales. Lo primero porque intenta ofrecer un marco metodológico para controlar la corrección y racionalidad de una decisión práctica sobre los conflictos. Lo segundo, porque ni dispone una específica resolución de antemano a esa colisión ni propone la instauración de una única respuesta correcta para esos supuestos. Sino que puede ser vista como una metodología (exigente es cierto) para arribar a mejores soluciones o, al menos, argumentativamente mejores y más controlables. En este sentido, sostiene Bernal (2005b, p. 110), la ponderación no fija "un procedimiento algorítmico que por sí mismo garantice la obtención de una única respuesta correcta en todos los casos"16.

15 En efecto, como dice Martínez (2010, p. 157) "que la relación sea condicionada significa que ciertas circunstancias C1 (por ejemplo, cuando la información es de relevancia pública por referirse a un funcionario en el ejercicio de su cargo) y uno de los principios (el derecho a la información) precede al otro (derecho al honor), pero esto no significa que uno de los derechos sea superior al otro, porque bajo otras circunstancias $\mathrm{C} 2$ (por ejemplo, cuando la información carece de relevancia pública o es manifiestamente injuriosa), el derecho al honor puede preceder a la libertad de información".

16 En otro trabajo, Bernal (2006, p. 57) sostiene que no "puede esperarse que, ni aun en el sistema constitucional más preciso, exista un única respuesta correcta para controversias de [la] magnitud y complejidad [que debe afrontar un Estado Constitucional de Derecho]".
Los atractivos de la posición son, a mi modo de ver, los siguientes: (i) busca establecer bases racionales para la resolución de los conflictos de derechos ${ }^{17}$; e (ii) intenta dar cuenta del hecho, efectuado por los tribunales ordinariamente, según el cual en un caso determinado tiene preferencia un derecho por sobre otro $y$, en uno nuevo, ese derecho preterido pueda resultar vencedor. Entonces, dado que los principios tienen diferente peso y que el conflicto entre ellos debería resolverse a partir de la dimensión de peso -y no según criterios de validez-ocurre que la aplicación de un principio por sobre otro no implica que el preterido sea declarado inválido. Solo significa que, dadas las circunstancias de su aplicación, uno tiene más peso relativo por sobre el otro; aunque en un caso individual futuro pueda ocurrir que, por ejemplo, la libertad de expresión pueda ser "vencida" por el derecho a la intimidad.

Así las cosas, la ponderación sería dirimente para configurar un conjunto de reglas que sean aptas para resolver el caso genérico de que se trate $^{18}$. Como expresa Moreso (2006, p. 20):

Las condiciones bajo las cuales un principio precede a otro constituyen el supuesto de hecho de una regla que expresa la consecuencia jurídica del principio precedente. Ahora bien, si las circunstancias C están delimitadas a partir de un supuesto concreto, parece que siempre es posible aducir otro supuesto en el que las circunstancias no coinciden y, entonces, la regla es válida únicamente para este supuesto.

17 Creo que a esto es a lo que se refiere Prieto (2004, p. 55) cuando afirma que la ponderación es "una forma de argumentación plausible cuando nos hallamos en presencia de razones justificatorias del mismo valor y tendencialmente contradictorias".

18 Martínez (2010) correctamente dice que la actividad ponderativa, en este nivel, consistiría únicamente en la elaboración de un conjunto de reglas que correlacionan las propiedades del universo de propiedades con la correspondiente solución normativa, que sería consecuencia jurídica del principio considerado prioritario en esas circunstancias. 


\section{Algunos problemas}

Sin embargo, los problemas no son menores. En primer lugar, se cuestiona si estamos ante un supuesto de interpretación jurídica. Guastini (2007, 2014), por ejemplo, entiende que se trata de un caso de "construcción jurídica" y, por ende, de legislación intersticial. Es que, adviértase, los principios no pueden ni constituirse en la premisa mayor del silogismo judicial ni pueden ser enfrentados, dada su heterogeneidad, con las reglas legislativas.

Es necesario entonces, recurrir a un procedimiento de concretización -i. e., debe ser transformado en una regla relativamente precisa-. Vale decir, es menester que el sujeto que esté en condiciones de aplicarlo determine las reglas implícitas que pueden obtenerse de él. De ahí que (i) debería decidir a cuáles clases de supuestos concretos se aplica y (ii) determinar sus excepciones. Y, en estos casos, existe siempre la posibilidad de adopción de decisiones subjetivas. En este sentido, y en segundo lugar, se trata de una decisión "altamente discrecional" 19 .

Para Guastini (1999, 2007, 2014) los casos de conflictos de derechos se caracterizarían por las siguientes notas:

1. Se trata de normas promulgadas, por lo general, en el mismo momento histórico.

19 De una opinión contraria es Barberis (2015). Para este autor, la ponderación es además de inevitable, una consecuencia de aceptar el pluralismo de valores. Vale decir, el pluralismo qua teoría metaética que admite la necesidad de especificar y ponderar en caso de conflicto de esos valores para proceder a su aplicación. En sus propias palabras: "je ne considère pas le balancement comme un choix arbitraire entre valeurs irrationnelles, opéré par des juges constitutionnels qui voudraient déposséder le Parlement de ses pouvoirs, mais plutôt comme un raisonnement rendu presque inévitable par le pluralisme des valeurs (en angl. values pluralism): théorie méta-éthique selon laquelle les valeurs morales, même formulées en principes constitutionnels, restent plurielles, génériques et conflictuelles, de telle sorte que les juges, afin de les appliquer, sont toujours contraints de les spécifier et de les pondérer en cas de conflit" (pp. 119-120).
2. Tienen la misma jerarquía normativa, por lo general constitucional.

3. Debe utilizarse con ocasión de un caso particular -i. e., conflicto en concreto-.

4. Se trata de los conflictos llamados por Alf Ross, "parciales" (i. e., solo un aspecto parcial del ámbito de aplicación de los principios en disputa es lo que colisiona). Un ejemplo al que recurre Martínez (2010) me parece, captura esta idea con precisión: supongamos que existe una norma $\mathrm{N} 1$ que prohíbe fumar a los pasajeros de los vuelos nacionales, mientras que otra norma N2 permite fumar a los pasajeros de los vuelos de trayecto superior a los dos mil kilómetros.

Ambas normas están perfectamente delimitadas -i. e., identifican las condiciones de aplicaciones, sus destinatarios, la obligación que imponen o el comportamiento que exigen, etc.-. No obstante, en caso en que el vuelo nacional (supuesto de hecho previsto por N1) tenga un trayecto superior a dos mil kilómetros (supuesto de hecho previsto por N2) ambas normas entran en colisión. El ejemplo, además de ilustrativo respecto de la antinomia parcial-parcial, prueba que es posible la existencia de estos conflictos aun cuando estemos en presencia de normas perfectamente delimitadas y precisas.

La consecuencia de esto, obvio, es la imposibilidad de proceder a su solución a partir de los criterios usuales empleados por los juristas para la resolución de los conflictos entre reglas -i. e., lex superior, lex posterior, lex specialis-. Para ello debe establecerse, en verdad, una jerarquía que tiene dos características que la complejizan teóricamente.

Por un lado, es axiológica y, por otro, es móvil. Lo primero porque la importancia ético-política del principio es lo que hace que uno prevalezca por sobre el restante; de modo tal que es menester la realización de un "juicio de valor comparativo" entre los principios a los efectos de la determinación de ese mayor peso relativo 
en términos ético-políticos (Guastini, 2014) ${ }^{20}$. Pero, a su vez, esa jerarquía es móvil en el sentido que es una "relación de valor inestable, mutable" (Guastini, 2014, p. 217). Y esto es así porque vale únicamente para el caso concreto al que se refiere y no para todos los casos en abstracto.

Es solo a partir de las circunstancias fácticas del mismo que se llega a la solución de que se trate; "el juez se limita a valorar la injusticia de las consecuencias de la aplicación de uno y otro principio en el caso concreto". Existiría, en el caso de la ponderación, además, un doble poder discrecional: al establecer la jerarquía axiológica y el peso de los valores en juego (Guastini, 1999, 2007, 2014).

Un tercer problema, según Guastini (1999, 2007, 2014) se vincula a los efectos de la ponderación en el tiempo; en cuanto proceso de construcción jurídica. Esos efectos, para él, son dobles y pueden verse desde una perspectiva diacrónica o sincrónica. En relación con lo primero, se sacrifica uno de los principios; y en cuanto a lo segundo, solo nos dice que en ciertos casos un principio puede ceder ante el otro y viceversa.

Además, el procedimiento de concretización de los principios -i. e., por el que se arriba a una regla-no puede ser un razonamiento deductivo $y$, así mismo, puesto que ellos por lo general expresan valores ético-políticos su interpretación, necesariamente, requerirá de un juicio de valor que reenvíe a doctrinas morales e ideológicas del intérprete (Guastini, 2007).

20 Algunos autores objetan la ponderación porque ella supone una posición filosófico-política no controvertida y actúa como si existiera un criterio común para la optimización; lo que, en rigor, desoye los debates que existen en sociedades políticas complejas respecto a cuestiones controvertidas de moralidad política. Para una visión en este sentido, véase Webber (2010). En cuanto a la importancia del desacuerdo en las sociedades contemporáneas y cómo su presencia inexcusable determina soluciones institucionales, véase Waldron (2005).

\section{Un intento de respuesta}

Ante esta objeción cabría cuestionarse si ella puede dar en el blanco. Esto es, si es cierta con respecto a la ponderación. Tengo algunas dudas. Si se reconoce que la ponderación no garantiza por sí misma la objetividad -i. e., rechaza la tesis de la única respuesta correcta- y si se admite que la exigencia de una hiperracionalidad es, a su vez, un acto de irracionalidad, y si también se reconoce que la ponderación a esto lo tiene asumido, cabría preguntarse si solo por eso la estrategia es desechable.

Mi intuición es que debería pensarse que la racionalidad exigida es una cuestión graduable; vale decir, es posible que se adopten decisiones judiciales más o menos racionales; más o menos subjetivas y más o menos controlables. El punto entonces, es interrogarse si la ponderación no puede brindar un marco posible de racionalidad en tanto metodología para proceder al control de los productos normativos de la autoridad.

En este sentido, Bernal (2006) efectúa una analogía con la lógica modal que, considero, resulta iluminadora. Es de notar que la lógica no dice nada de las premisas desde las que se parte para llegar a una conclusión. Solo se encarga de establecer la corrección de la deducción de que se trate; así dirá si la conclusión pertinente es una derivación necesaria de las premisas asumidas, o bien si no lo es. Ahora, que no fije la corrección de las premisas, que la conclusión pudiera llegar a ser falsa según un criterio de verdad por correspondencia, no dice nada en contra del criterio formal para el análisis de la estructura del razonamiento.

Como enuncian Guibourg, Echave y Urquijo (2002) la lógica -y en la analogía, la ponderación- es como la aritmética en un restaurante: no sirve de nada quejarse porque la cuenta es alta. No obstante, si uno sabe matemáticas puede detectar un error en la suma. La lógica cumple una función similar; puede controlar la derivación o deducción necesaria de una conclusión a partir de un conjunto de premisas. 
Si la analogía es correcta, es cierto que la ponderación no puede establecer la existencia de una única respuesta verdadera al problema práctico de que se trate -i. e. un conflicto de derechos-. Sin embargo, puede ser un adecuado medio de control de la racionalidad de las decisiones en materia de conflictos de derechos. Admitiendo, claro, el empleo de la subjetividad del juez. Aquí, por supuesto, surge un problema importante en esta defensa matizada que ensayo.

Podría objetarse una supuesta inestabilidad en mi reconstrucción. Según la crítica, es contradictorio aceptar (i) el control de racionalidad de una decisión $\mathrm{D}_{j}$ y que (ii) carecemos de un criterio único para identificar las mejores razones que justificarían $\mathrm{D}_{j}^{21}$. Pienso que, no obstante, si se admite que la ponderación puede funcionar como un criterio formal que permita la identificación de los pasos en la argumentación a la que recurre el juzgador para determinar su decisión, se trata de una herramienta sumamente útil. De tal suerte, es una metodología válida para controlar racionalmente aquello que es controlable: cómo avanza el razonamiento del juzgador en cada una de las etapas de su argumentación y demuestra si emplea las herramientas dogmáticas de forma correcta.

Entonces, una vez que se aceptan las limitaciones propias de la exigencia de racionalidad y se recuerda que solo se trata de una estructura formal de control a esos fines, algunas de las objeciones que se le han formulado pueden ser disipadas. Y es que, en procura de garantizar la racionalidad, no se le puede exigir a la metodología una actividad -o criterio- que, dadas las altas exigencias a las que se le somete, para poder dar cumplimiento a ello deba tornarse irracional ${ }^{22}$. En suma, no es posible exigirle a una

21 Una objeción semejante, me parece, puede encontrarse en Moreso (2010). Este autor le reprocha al rechazo ferrajoliano al cognoscitivismo ético y al objetivismo moral, que es una posición inestable porque ofrecería un "espacio para la argumentación racional, pero no tenemos un criterio para establecer cuáles son mejores razones" (p. 191).

22 Sobre esto, véase Bernal (2006) metodología que en rigor es puramente formal, el cumplimiento de condiciones de racionalidad tan exigentes y conjuntivamente imposibles que, en verdad, la coloca ante un supuesto de irracionalidad por hiperracionalidad.

\section{V. ¿Particularismo?}

Otra cuestión, independiente de lo dicho pero relacionada, es que en estos casos de lo que se trata es de proponer supuestos de instanciación de una concepción particularista del razonamiento (moral y jurídico). Vale decir, se niega la existencia y pragmática de normas universales que puedan tener la virtud de establecer la corrección moral de las acciones.

En este sentido, una doctrina de este tipo, como dice Guastini (2007), se funda en el valor de la equidad -i. e., justicia del caso concreto- $y$, por tanto, los jueces no deberían aplicar las normas ciegamente; al contrario, debieran buscar para cada caso la solución justa. Y, así, lo que deben hacer los jueces es (i) descartar la interpretación literal e (ii) introducir excepciones en aquellos supuestos en los que la aplicación de las reglas conllevaría una solución que se advierte como injusta (Guastini, 2007, 2014).

Es que siempre se trata de una operación que será dependiente del contexto de producción (estrategia particularista) que motivó el caso de que se trate. La vinculación con lo anterior es estrecha. Es aceptado que no puede dudarse de la racionalidad y corrección que implica la derivación deductiva y necesaria de una consecuencia a partir de sus premisas. Ahora bien, una estrategia particularista no podría dar cuenta de esta operación pues siempre, y en todo caso, tendría problemas para dar una respuesta consistente respecto de la racionalidad o arbitrariedad de una decisión.

Es que aquí parecería que la ponderación se apropia de los problemas del particularismo (jurídico o moral): "no puede ofrecer una explicación satisfactoria de la idea de justificación" (Orunesu, 
2012, p. 90, con cita a Bayón, 2003, p. 305) ${ }^{23}$. No podría explicar cuáles son las características que permiten establecer las circunstancias del caso concreto normativamente relevantes para decidir un caso particular y, al mismo tiempo, afirmar que no se trata de una decisión arbitraria. Esto porque no recurre a normas universales que provean de una justificación.

Moreso (2006) intentó eludir esta objeción. Para eso, sostuvo que ponderación es un paso previo a la subsunción. La salida de la objeción es necesaria, para él, porque de lo contrario estaríamos presos de un dilema: o tenemos justificación subsuntiva de las decisiones con el precio de asumir la posibilidad de una reconstrucción completa y consistente de los contenidos regulados por las pautas que establecen derechos, una reconstrucción inalcanzable para seres humanos como nosotros o bien tenemos ponderación en los casos individuales, abierta siempre a la acusación de arbitrariedad o, al menos, imposibilidad de control racional. Según su posición la ponderación facilita

(...) pasar de las normas que establecen derechos fundamentales, que tienen la estructura de principios - pautas con la condiciones de aplicación abiertas-, a reglas -pautas con las condiciones de aplicación clausuradas-con las cuales es posible llevar a cabo la subsunción, en el ámbito de un problema normativo determinado (Moreso, 2006, p. 826).

Satisfecha la dimensión de los principios, el aplicador de derechos fundamentales construiría una regla general sobre la cual habrá de subsumir el caso individual que tiene ante sí. Para ello, Moreso (2006) formuló una estrategia en cinco pasos:

1. Delimitación del universo de discurso -i. e., establecer el ámbito del problema normativo de que se trate-.

23 Cfr. Orunesu (2012, p. 90, con cita a Bayón). Adviértase que para esta posición por justificación debe entenderse aquel procedimiento que determina que una conclusión es una derivación necesaria de ciertas premisas.
2. Identificación de las pautas prima facie aplicables.

3. Consideración y determinación de casos paradigmáticos del ámbito normativo que tendrían la función de constreñir las reconstrucciones admisibles -i. e., las reconstrucciones de los casos paradigmáticos adecuadamente-.

4. Establecer cuáles son las propiedades relevantes del universo de discurso.

5. Formulación de reglas que resuelvan de modo unívoco los casos del universo de discurso.

Me seduce mucho la propuesta. El atractivo, obvio, es que parecería compatibilizar dos formas del razonamiento moral y jurídico por las que nos sentimos fuertemente atraídos: particularismo y universalismo. Y ello es una consecuencia de ver a la ponderación como un paso previo a la subsunción. En rigor, la consigna es no abandonar las propiedades características de un caso que nos llevan a pensar de modo particularista; sin que, por eso, reniegue de la subsunción, que nos invita a pensar universalistamente. Ahora, una cosa es que la estrategia sea seductora y otra bien distinta es que sea correcta.

Más allá de todo esto y de los esfuerzos intelectuales dirigidos por los autores a este fin, me parece que se trata de la racionalización de una operación puramente discrecional. Y lo es, como dice Guastini (2007, 2014), en dos supuestos: al momento de fijar la jerarquía axiológica de los principios frente al caso concreto y al indicar cuáles son las razones que se identifican para el cambio de los valores. En todo caso, el esfuerzo de Moreso (2006) es demostrativo de esto. Si bien intenta la limitación del aplicador, no es posible obviar esta discrecionalidad en un paso tan fundamental en su construcción como es en la identificación de los que llama "casos paradigmáticos".

Dada la presencia de valores de moralidad política que son controvertidos y controvertibles en una sociedad pluralista, los supuestos "casos paradigmáticos" no serán sino relativos a una 
determinada concepción metaética y de ética normativa. Las posibilidades de identificación de esos casos, sin arribar a acuerdos sustentables y sostenidos sobre estos ámbitos es un terreno, a decir verdad, bastante volátil. Es que, si en aquel dominio normativo no se lograsen los acuerdos necesarios convencionalmente para poder determinar, en primer lugar, qué es lo que hace que un caso sea paradigmático y cómo esto se vincula con controvertidas cuestiones sobre el estatus lógico de los enunciados morales, es dudoso que la empresa pueda lograr su finalidad última: acotar las posibilidades subjetivas y discrecionales del intérprete. Esto, nuevamente, nos deja en manos de Guastini (2007, 2014).

Esto, también, me parece que es una consecuencia de las asunciones del argumento. En efecto, este no puede progresar sin una distinción fuerte entre principios y reglas. Sin embargo, no es para nada claro que esto sea, en realidad, así. Al contrario, muchos autores se decantan por aseverar que la diferencia entre ellos es únicamente de grado ${ }^{24}$. Y si esto fuera así, es difícil identificar cuáles serían los casos sujetos a ponderación y cuáles serían los casos sujetos a subsunción. Nuevamente nos encontramos ante la discrecionalidad del agente $y$ ante serias dificultades para controlarlo.

Además, debe adicionarse un problema, no conceptual sino empírico: en muchos casos los jueces tratan a las reglas como principios y a los principios como reglas. La imagen que refleja sobre el derecho y su autoridad esta cuestión no es para nada halagüeña. Y allí es donde subyacen los problemas vinculados a la autoridad y legitimidad de un juez en una democracia para proceder de este modo. Pues debería recordarse que la

24 La calificación de una norma como regla o como principio no depende de connotaciones intrínsecas ontológicas o estructurales, antes bien, es relativa a la interpretación del enunciado que expresa la norma de que se trata (cfr. Comanducci, 1998). En el ámbito de la teoría constitucional, por todos, véase Ferreres (2007). Para críticas a la distinción fuerte entre "principios" y "reglas" véase Ferrajoli (2012).
(...) relevancia de la autoridad impone la subordinación de los jueces a las decisiones del legislador y son infieles a su autoridad aquellos jueces que toman a una regla como si fuese un principio o a un principio como si fuese una regla (Navarro, 2005, p. 35).

El punto es que, si no es tan clara la distinción estructural entre unos y otras, como algunos autores suponen, la posibilidad de tratamiento diverso injustificado, con probabilidad de dañar la autoridad democrática de una comunidad política plural, se hace presente.

\section{Cierre}

En este trabajo intenté hacer una reconstrucción de algunas críticas dirigidas a la ponderación. En especial, me detuve en una de ellas: su presunta irracionalidad. La respuesta a este interrogante, sin embargo, de mi parte fue negativa. No creo que sea irracional la ponderación, al menos en el sentido que los críticos entienden la racionalidad. Y no lo es porque la exigencia de hiperracionalidad, aunque no lo parezca, es un acto de irracionalidad. Entonces, traté de decir que, cuando se le exige racionalidad en un nivel tan concreto, específico y exigente como el que describí, se procura que ella rompa con el ideal al que debería rendirle cuentas.

Así mismo, ofrecí una comprensión modesta $y$, a la vez, exigente de la ponderación. Según mi criterio debe ser vista únicamente como una estructura formal de control para las decisiones judiciales. Pese a lo cual, no creo que pueda excluir (es más, entiendo que no lo intenta) las subjetividades del juzgador al momento de resolver los conflictos de derecho que se le presentan.

Ahora bien, al final del trabajo, intenté mostrar que aun cuando esto fuera correcto, un problema distinto hace su aparición. No se trata ya de un análisis de metateoría del derecho o de epistemología jurídica sino que, al contrario, es 
un problema de índole filosófico-política ${ }^{25}$. Y es este el dominio normativo al que la discusión sobre este tema debería trasladarse. Para mí, en este supuesto, la filosofía política debería determinar la posición institucional de jueces constitucionales en una democracia cuando se advierte: que no están vinculados por normas constitucionales - porque carecen de ellas-, que la presencia de elementos subjetivos y discrecionales es obvia y que, en fin, la posibilidad de manipulación del material normativo con el que trabajan es muy factible, posible y obvia.

El peligro es que, con jueces infieles en esta materia, no se aplica la ponderación en un sentido preciso y, lo que es peor, se obtura la legitimidad de la propia Constitución desde un punto de vista democrático ${ }^{26}$. Ninguno de estos escenarios es, entonces, prometedor. Pero analizar las razones democráticas de por qué esto es así, merece otro escrito ${ }^{27}$.

\section{Referencias}

Alexy, R. (2008). Teoría de los derechos fundamentales ( $2^{\mathrm{a}}$ ed.). Madrid: Centro de Estudios Constitucionales.

Atienza, M. (2012). Dos versiones del constitucionalismo. Doxa. Cuadernos de Filosofía del Derecho, 34, pp. 73-88.

Atienza, M. \& Ruiz, J. (1996). Las piezas del derecho: teoría de los enunciados jurídicos. Barcelona: Ariel.

25 Es en este mismo sentido en el que Pino (2014, p. 599) refiere que en el ámbito anglosajón la preocupación central por este tema pasa por: "il problema del grado di discrezionalità associato a questa tecnica argomentativa, con conseguente spostamento di potere decisionale, in delicate materia di public policy, da parlamento e governo ad organi non rappresentativi; la tensione tra il principio di proporzionalità $e$ il requisito di inviolabilità dei diritti fondamentali; i vantaggi e gli svantaggi dell'utilizzo del test di proporzionalità rispetto al ricorso ad altre tecniche decisionali".

26 Respecto de esta posición, véanse Post y Siegel (2009).

27 Un análisis profundo y completo de las tensiones entre constitucionalismo y democracia está en Bayón (2010). Puede verse también, Mocoroa (2013).
Balkin, J. (2011). Living originalism. Cambridge: The Belknap Press of Harvard University Press.

Balkin, J. \& Levinson, S. (2010). Los cánones en el derecho constitucional: qué son y cómo se conforman. En: M. Carbonell \& L. García (eds.). El canon neoconstitucional. Bogotá: Universidad Externado de Colombia, (pp. 37-96).

Barberis, M. (2015). Le néoconstitutionnalisme existe-t-il? Revus. Journal for Constitutional Theory and Philosophy of Law, 25, pp. 101-124.

Bayón, J. (2003). ¿Por qué es derrotable el razonamiento jurídico? En: J. Bayón \& J. Rodríguez. Relevancia normativa en la justificación de las decisiones judiciales. Bogotá: Universidad Externado de Colombia (pp. 263-312).

Bayón, J. (2010). Democracia y derechos: problemas de fundamentación del constitucionalismo. En: M. Carbonell \& L. García (eds.). El canon neoconstitucional (409-476). Bogotá: Universidad Externado de Colombia.

Bernal, C. (2005a). "Racionalidad, proporcionalidad y razonabilidad en el control de constitucionalidad de las leyes". En: C. Bernal. El derecho de los derechos. Escritos sobre la aplicación de los derechos fundamentales (pp. 59-92). Bogotá: Universidad Externado de Colombia.

Bernal, C. (2005b). La ponderación como procedimiento para interpretar los derechos fundamentales. En: C. Bernal. El derecho de los derechos. Escritos sobre la aplicación de los derechos fundamentales (pp. 93-111). Bogotá: Universidad Externado de Colombia.

Bernal, C. (2006). La racionalidad de la ponderación. Revista Española de Derecho Constitucional, 26(77), pp. 51-75.

Caminos, P. (2014). El principio de proporcionalidad: ¿una nueva garantía de los derechos 
constitucionales? Revista Electrónica del Instituto de Investigaciones "Ambrosio L. Gioja”, VIII(13), pp. 51-74.

Comanducci, P. (1998). Assaggi di metaética due. Turín: Giappichelli.

Ferrajoli, L. (2012). Constitucionalismo principialista y constitucionalismo garantista. Doxa. Cuadernos de Filosofía del Derecho, 34, pp. $15-54$.

Ferreres, V. (2007). Justicia constitucional y democracia (2a ed.). Madrid: Centro de Estudios Constitucionales.

Guastini, R. (1999). Los principios en el derecho positivo. En: R. Guastini. Distinguiendo. Estudios de teoría y metateoría del derecho (pp. 142-178). Barcelona: Gedisa.

Guastini, R. (2007). Teoría e ideología de la interpretación constitucional. Madrid: Trotta.

Guastini, R. (2014). Interpretar y argumentar. Madrid: Centro de Estudios Políticos y Constitucionales.

Guibourg, R., Echave, D. \& Urquijo, M. (2002). Lógica, proposición y norma. Buenos Aires: Astrea.

Habermas, J. (1998). Facticidad y validez. Barcelona: Trotta.

Martínez, D. (2010). Metodología jurídica y argumentación. Madrid: Marcial Pons.

Mocoroa, J. (2013). "Derechos y justicia constitucional" revisitado. Revista Discusiones, XII, pp. 121-193.

Moreso, J. (2005). Sobre los conflictos entre derechos. En: M. Carbonell \& P. Salazar (coords.). Garantismo. Estudios sobre el pensamiento jurídico de Luigi Ferrajoli (pp. 159-170). Barcelona: Trotta.
Moreso, J. (2006). Dos concepciones en la aplicación de las normas de derechos fundamentales. Revista Direito GV, 2(2), pp. 13-30.

Moreso, J. (2010). Conflictos entre derechos constitucionales y maneras de resolverlos. Arbor. Ciencia, Pensamiento y Cultura, CLXXXVI(745), septiembre-octubre, pp. 821-832.

Navarro, P. (2005). Interpretación del derecho y modelos de justificación. Revista Escuela de Derecho, 6(6), pp. 11-44.

Orunesu, C. (2012). Positivismo jurídico y sistemas constitucionales. Madrid: Marcial Pons.

Pino, G. (2009). Conflictos entre derechos fundamentales. Una crítica a Luigi Ferrajoli. Doxa. Cuadernos de Filosofía del Derecho, 32, pp. 647-664.

Pino, G. (2014). Proporzionalità, diritti, democrazia. DeS, 3, pp. 597-628.

Post, R. \& Siegel, R. (2009). Democratic constitutionalism. En: J. Balkin \& R. Siegel (eds). The Constitution in 2020 (pp. 25-34). Nueva York: Oxford University Press.

Prieto, L. (2004). El constitucionalismo de los derechos. Revista Española de Derecho Constitucional, 24(71), pp. 47-72.

Ruiz, J. (2009). Principios, objetivos y derechos. Otra vuelta de tuerca. En: M. Atienza \& J. Ruiz (eds.). Para una teoría postpositivista del derecho (pp. 87-126). Lima: Palestra y Temis.

Waldron, J. (2005). Derecho y desacuerdos. Madrid: Marcial Pons.

Webber, G. (2010). Proportionality, balancing and the cult of the constitutional rights scholarship. Canadian Journal of Law and Jurisprudence, 23(1), pp. 179-202. 